\title{
Influence of alpha acids hop homologues of bitter and aromatic varieties on beer quality
}

\author{
Lidia Protsenko ${ }^{1}$, Serhii Ryzhuk ${ }^{1}$, Mykola Liashenko ${ }^{1}$, \\ Oleksandr Shevchenko², Svitlana Litvynchuk ${ }^{2}$, \\ Liliia Yanse ${ }^{3}$, Henrikh Milosta ${ }^{4}$
}

\author{
1 - Polissya Institute of Agriculture of NAAS of Ukraine, Zhytomyr, Ukraine \\ 2 - National University of Food Technologies, Kyiv, Ukraine \\ 3 - National Academy of Agrarian Sciences of Ukraine, Kyiv, Ukraine \\ 4 - Educational institution "Grodno State Agrarian University", Grodno, Belarus
}

\section{Keywords:}

Hop

Alpha-acids

Cohumulone

Wort

Beer

\section{Article history:}

Received

08.08.2019

Received in revised

form 20.12.2019

Accepted

30.06.2020

\section{Corresponding}

author:

Svitlana Litvynchuk

E-mail:

Litvynchuk@

nuft.edu.ua

DOI:

10.24263/2304-

974X-2020-9-2-13

\section{Abstract}

Introduction. The aim of the study was to study the bitter substances of hops to establish the dependence of the bitterness of the wort and the quality of beer hops on the quantitative and qualitative composition of alpha-acids hop homologues, in particular, on the content of cohumulone in alpha-acids.

Materials and methods. Aromatic and bitter hops with different content of cohumulone in the composition of alpha-acids and beer made from it were studied. High-performance liquid chromatography was used to determine the amount and composition of hop bitter substances and products of their transformation in the brewing process as well as spectrophotometric methods of quality control of the bitterness of hopped wort and finished beer.

Results and discussion. It is noted that alpha-acids of the studied varieties contain a wide range of cohumulone content: from $19.6 \%$ in hops of Alta variety to $43.8 \%$ in hops of Ruslan variety. Establishing the relationship between the quantity and quality of bitter substances of hops and the bitterness and quality of hopped wort and beer show that with increasing mass fraction of cohumulone in the composition of alpha-acids of aromatic hops by $1 \%$ with a ratio of beta-acids to alpha-acids of 1.11-1.34 the value of bitterness of the wort hopped by them increases from $0.69 \%$ for Gaidamats'kyi variety to $1.05 \%$ for Slovyanka variety. In bitter hops, the ratio of beta-acids to alpha-acids is much lower and is $0.51-0.74$. Analysis of the relationship between the growth of cohumulone and the change in the bitterness of the wort hopped with bitter varieties shows that with increasing the share of cohumulone in the alpha-acids of bitter hops by $1 \%$ the bitterness of hop wort increases from $0.19 \%$ for Ruslan to $0.38 \%$ for the variety Promin'. Between the bitterness of the wort and the amount of cohumulone with hops when using both bitter and aromatic varieties, there is a strong relationship as evidenced by the correlation coefficient which is for bitter varieties $r=0.90 \pm 0.10$, for aromatic $r=0.98 \pm 0.20$. In the formation of the bitterness of the wort, hopped with aromatic varieties from the ratio of beta-acids to alpha-acids is more than one, the role of beta-acid compounds is much higher compared to bitter varieties.

Conclusions. When used for hop wort of bitter type hops with different composition of alpha-acids, their use is more effective in varieties with a high content of cohumulone. 


\section{- Food Technology -}

\section{Introduction}

Previous research [1,3-7] show that high-quality beer with a characteristic bitter taste and aroma can be obtained only with the use of hops and products of its processing of certain breeding varieties. This is due to the peculiarities of their biochemical composition, and above all, with the quantitative content and qualitative composition of bitter substances, polyphenolic compounds and essential oil of hops aromatic and bitter varieties [2, 8-10]. Different ratio of components of these compounds affects taste and aromatic properties of beer $[11,15]$.

Bitter substances, polyphenols and aromatic essential oils of hops take part in the formation of taste and aromatic properties of beer [1-3, 8-15]. The specific qualities of beer are most affected by isomers of the original bitter substances of hops, which are contained in cones in small quantities, and are formed during the boiling of wort with hops $[1-3,7]$. Isoalpha-acids are quantitatively the most important fraction of hops in beer. They give a typical bitter taste, and depending on the desired bitterness and type of beer, their concentration ranges from 10 to $100 \mathrm{mg} / \mathrm{l}$ [16]. Iso-alpha-acids are more soluble in beer wort and more bitter than alpha-acids and form $90-95 \%$ of the total bitterness of beer [1, 7]. In addition to the isomerization reaction, iso-alpha-acids undergo both oxidative and non-oxidative transformations. As a result, both the intensity and the quality of the bitterness of beer are negatively affected [16]. Trans-iso-alpha-acids in beer are significantly less stable than their counterparts. At the same time, a sharp, lingering bitter taste develops and an aroma defect is formed, which occurs during the aging of beer [16]. The formation of volatile substances from iso-alpha-acids after beer aging is explained by the process of cyclization of trans-isoalpha-acids into tri- and tetracyclic decomposition products. These non-volatile breakdown products of trans-iso-alpha-acids have only recently been identified [16].

According to the results of research, in the formation of the bitterness of beer $[1,3,7$, 16] in the hop the main importance are alpha-acids, which consist of humulone, cohumulone, adhumulone, prehumulone and posthumulone. Insoluble alpha-acids are converted at high temperatures by hopping the wort into soluble iso-alpha-acids (isohumulone, isocohumulone, isoadhumulone), giving the beer a bitter taste $[3,8,16]$. Moreover, depending on the length of the side chains of the acyl residue in the second carbon atom of the hexadiene ring changes the solubility of alpha-acid homologues, and the rule is the longer the side chain, the lower the solubility. Therefore the solubility of cohumulone is much higher than that of humulone and adhumulone $[1,3,7,16]$. When studying the bitterness and iso-alpha-acid content of some brands of Brazilian and North American beer [17] it was found that the isoadhumulone fraction was a fraction of lower concentration in all samples, and most samples showed a higher concentration of isohumulone. The range of isohumulone ranged from 3.0 to 17.0 $\mathrm{mg} / \mathrm{l}$.

Not all alpha-acids have a positive effect on the quality of bitterness in beer. It is known $[1,3,7,16,17]$ that isohumulone, isocohumulone and isoadhumulone have approximately the same degree of bitterness. However, when the wort is boiled with hops, the isomerization of alpha-acid homologues proceeds with different formation of isocomponents. Of great importance is the quantitative ratio of homologues of alpha-acids. Czech hops (Zaaz variety) are characterized by a high content of humulone and adhumulone (up to $80 \%$ ), while in German and American high-resin varieties such as Hercules, Tomahawk is dominated by cohumulone (up to $50 \%$ ).

Cohumulone is converted to the isomer better than other components of alpha-acids. But this faction is attributed a negative role in the formation of the bitterness of beer [18]. However, although in Czech varieties the composition of alpha-acids is dominated by 
humulone, the bitterness of Czech beer is represented mainly by isohumulone. In the processing of hops varieties with a predominant content of cohumulone, beer contains mainly isocohumulone, and the quality of bitterness according to $\mathrm{M}$. Kusche and others. much worse [19-20]. It is possible that the qualitative difference in the composition of the original alphaacids is also the reason for the known difference in the quality of beer, which is very significant. But the question remains whether varieties of hops with a high content of cohumulone create more bitterness in beer. It follows from the above that the selection of varieties with the optimal composition of bitter substances for beer with excellent and high quality bitterness is a topical issue for brewers of the American Association [18], European brewers [19] and Ukrainian beer producers [21].

As can be seen from the analysis of literature sources the composition of bitter substances of hops of European and American varieties and the influence of their homologues on the quality of beer bitterness are well studied. Instead, there have been almost no similar studies with Ukrainian hop varieties. In this regard to ensure stable and high-quality bitterness of beer it is important to investigate the effect of certain components of alpha-acids of Ukrainian hops on the qualitative and quantitative indicators of the drink.

The aim of the work was to study the bitter substances of hops, to establish the dependence of the bitterness of the wort and the quality of beer hops on the quantity and quality of homologues of alpha-acids of Ukrainian and European varieties, in particular the content of cohumulone in alpha-acids.

\section{Materials and methods}

The cones of pressed hops of Ukrainian and European selection of typical representatives of the aromatic group of varieties were used for research: Slovyanka, Nationalnyi, Zaaz, Gaidamats'kyi and bitter: Alta, Magnum, Northern Brewer, Promin', Ksanta, Ruslan and beer made from them.

Methods of research of bitter substances of hops. Bitter substances of hops from cones were extracted with an organic solvent - methanol [22]. The ratio between the mass of hop cones and the extractant was 1:10. The amount of alpha and beta-acids and the content of cohumulone in the composition of alpha-acids were determined by the international method of EMU 7.7 using liquid chromatography HPLC [23]. Chromatography was performed using a liquid chromatograph Ultimate 3000 with a UV detector at a temperature of $35^{\circ} \mathrm{C}$ [1]. Used a column measuring $100 \times 2.1 \mathrm{~mm}$ which was filled with sorbent Pinacle DV C18 $3 \mu \mathrm{m}$ [1]. A solution of methanol, water and acetonitrile in the ratio 38:24:38 was used as the mobile phase [24].

The international standard ICF-3 was used to quantify the components of bitter substances [23].

Methods for the presentation of wort and beer. Beer from the studied hop samples was produced at the mini-breweries of the Department of Hop and Beer Biochemistry of the Polissya Institute of Agriculture of the National Academy of Agrarian Sciences of Ukraine with a yield of 100 liters, which fully simulates the conditions of real enterprises on a scale of 1: 100, compact and allows to achieve research goals [2].

Rationing of hops in mini-brewery was performed on the content of alpha-acids in them. The wort was prepared from $100 \%$ barley malt. The hopping was performed at the rate of 60 mg of bitter substances per 1 liter of wort. After complete set the wort was boiled for 30 
minutes. Then in the wort in each variant of the experiment was made hops of the presented varieties in two steps: $85 \%$ at the beginning of hopping, $15 \%-15$ minutes before the end of hopping. The total boiling time of hop wort was 90 minutes [21].

The bitterness of the wort formed during its boiling with hops, as a result of extraction and isomerization of bitter substances of hops, was determined on a spectrophotometer according to the method of EMU 8.8 (International method of IM) [23]. The method is based on measuring the optical density of the isooctane extract obtained by extracting bitter substances from acidified beer wort or beer with isooctane (2,2,4-trimethylpentane), on a spectrophotometer at a wavelength of $275 \mathrm{~nm}$ against isooctane [23]. The value of the rate, the number of turns in the units of the international scale for the value of the terms of the EBC were estimated on the basis of the optical index of the weight, as in the international units of the unit - EBC [23].

The beer quality was evaluated organoleptically at the tasting, hardened tasting committee of the designated Institute, for the 25-point integrated assessment [21].

\section{Results and discussion}

\section{Bitter substances of hops of aromatic and bitter varieties}

Complex biochemical studies of hops of different breeding varieties made it possible to establish that hops of aromatic and bitter varieties have different biochemical composition, and hence different brewing value.

The most important among bitter substances are alpha-acids, which in the process of isomerization during hop hopping are converted into iso-alpha-acids, the main compounds of beer bitterness. When the wort is hopped with freshly harvested hops almost $90 \%$ of the bitterness of beer is formed as a result of isomerization of alpha-acids into iso-alpha-acids, as a result of which the hexadiene ring of alpha-acids is converted into pentadiene iso-alphaacids, giving beer a bitter taste $[3,7,8,16]$. The amount of alpha-acids is the main pricing factor in the evaluation of hops and hop products.

The biochemical characteristics of bitter substances of the studied varieties of the bitter group of hops are given in Table 1. From the data of table 1 it is seen that in the hops of the studied varieties the content of alpha-acids ranges from 9.5 to $11.2 \%$. Most alpha-acids were found in Magnum hops $-11.2 \%$.

Characteristics of bitter substances of hops of bitter group varieties

\begin{tabular}{|c|l|c|c|c|c|}
\hline No & \multicolumn{1}{|c|}{ Variety of hop } & $\begin{array}{c}\text { Contents } \\
\text { alpha- } \\
\text { acids, \% }\end{array}$ & $\begin{array}{c}\text { Cohumulone } \\
\text { in the } \\
\text { composition } \\
\text { alpha- } \\
\text { acids, \% }\end{array}$ & $\begin{array}{c}\text { Contents } \\
\text { beta- } \\
\text { acids, \% }\end{array}$ & $\begin{array}{c}\text { The ratio of } \\
\text { beta/alpha- } \\
\text { acids }\end{array}$ \\
\hline 1 & Alta (Ukraine) & 10.3 & 19.6 & 3.8 & 0.53 \\
\hline 2 & Magnum (Germany) & 11.2 & 23.1 & 5.3 & 0.51 \\
\hline 3 & $\begin{array}{l}\text { Northern Brewer } \\
\text { (Great Britain) }\end{array}$ & 9.5 & 27.8 & 3.9 & 0.52 \\
\hline 4 & Promin' (Ukraine) & 9.6 & 29.6 & 4.1 & 0.53 \\
\hline 5 & Ksanta (Ukraine) & 9.9 & 34.7 & 6.0 & 0.74 \\
\hline 6 & Ruslan (Ukraine) & 9.7 & 43.8 & 5.7 & 0.73 \\
\hline
\end{tabular}


The content of beta-acids in the studied varieties is from $3.8 \%$ in hops of the Alta variety to $6.0 \%$, respectively, in the Ksanta variety. Beta-acids are not bitter in taste but in the process of oxidation, compounds are formed that have a pleasant bitterness. One of their main properties is a high antiseptic effect which is important to increase the biological stability of beer during storage [8-15]. The coefficient of aromaticity between the content of beta- and alpha-acids for this group of varieties is from 0.51 to 0.74 which is less than one.

Not all alpha-acids have a positive effect on the quality of bitterness in beer. Cohumulone is converted to the isomer better than other components of alpha-acids, so the solubility of cohumulone is much higher than humulone and adhumulone $[1,3,7,16]$. But this faction is attributed a negative role in the formation of the bitterness of beer [18].

The analysis of table 1 shows that the selected varieties of bitter hops have a slight deviation of alpha-acids and the ratio of beta-acids to alpha-acids is less than one, instead have a wide range of cohumulone content: from $19.6 \%$ in cones of Alta up to $44.1 \%$ in the Ruslan variety, which will allow to investigate its influence on the quality of beer.

Bitter substances of typical representatives of aromatic varieties of hops were also studied (Table 2).

Characteristics of bitter substances of aromatic varieties of hops

Table 2

\begin{tabular}{|c|l|c|c|c|c|}
\hline № & Variety of hop & $\begin{array}{c}\text { Contents } \\
\text { alpha- } \\
\text { acids, \% }\end{array}$ & $\begin{array}{c}\text { Cohumulone } \\
\text { in the } \\
\text { composition } \\
\text { alpha- } \\
\text { acids,\% }\end{array}$ & $\begin{array}{c}\text { Contents } \\
\text { beta- } \\
\text { acids,\% }\end{array}$ & $\begin{array}{c}\text { Ratio of } \\
\text { beta/alpha- } \\
\text { acids }\end{array}$ \\
\hline 1 & $\begin{array}{l}\text { Nationalnyi } \\
\text { (Ukraine) }\end{array}$ & 5.1 & 20.1 & 5.7 & 1.11 \\
\hline 2 & $\begin{array}{l}\text { Slovyanka } \\
\text { (Ukraine) }\end{array}$ & 5.5 & 22.1 & 7.4 & 1.34 \\
\hline 3 & $\begin{array}{l}\text { Zaaz } \\
\text { (Czech Republic) }\end{array}$ & 5.3 & 25.3 & 6,8 & 1.28 \\
\hline 4 & $\begin{array}{l}\text { Gaidamats'kyi } \\
\text { (Ukraine) }\end{array}$ & 4.2 & 29.6 & 5.3 & 1.27 \\
\hline
\end{tabular}

In the samples of hops of the studied varieties, the content of alpha-acids ranges from 4.2 to $5.5 \%$ which is much less compared to bitter varieties. A characteristic feature of cone hops of aromatic varieties, in contrast to bitter, is a high positive coefficient of aromaticity between the content of beta and alpha-acids, ranging from 1.11 to 1.34. Among the studied varieties, hop cones of Slovyanka and Zaaz varieties are characterized by the highest indicator of aromaticity.

From the analysis of table 2 shows that the selected varieties of hops of aromatic type have a ratio of beta-acids to alpha-acids greater than one. The content of cohumulone in the composition of alpha-acids ranges from $20.1 \%$ in the cones of the Nationalnyi variety to $29.6 \%$ in the Gaidamats'kyi variety which will allow to investigate its effect on the quality of beer. 


\section{Influence of cohumulone bitter and aromatic varieties of hops on the quality of the wort}

Experimental beer samples were made with the studied hop varieties. The amount of alpha-acids and cohumulone up to 1 liter of wort was calculated.

Since the hop was carried out with bitter hops at the rate of $60 \mathrm{mg}$ of bitter substances per 1 liter of wort, the same amount of alpha-acids is added to the wort - about $60 \mathrm{mg} / \mathrm{l}$ but different amount of cohumulone: from $11.8 \mathrm{mg} / \mathrm{l}$ with Alta hops to $26.3 \mathrm{mg} / \mathrm{l}$ with the Ruslan variety. In this case, the value of the bitterness of the hopped wort also varies from 33.2 units EBC (variety Alta) up to 41.3 units EBC when using Ksanta hops which is shown in Figure 1.

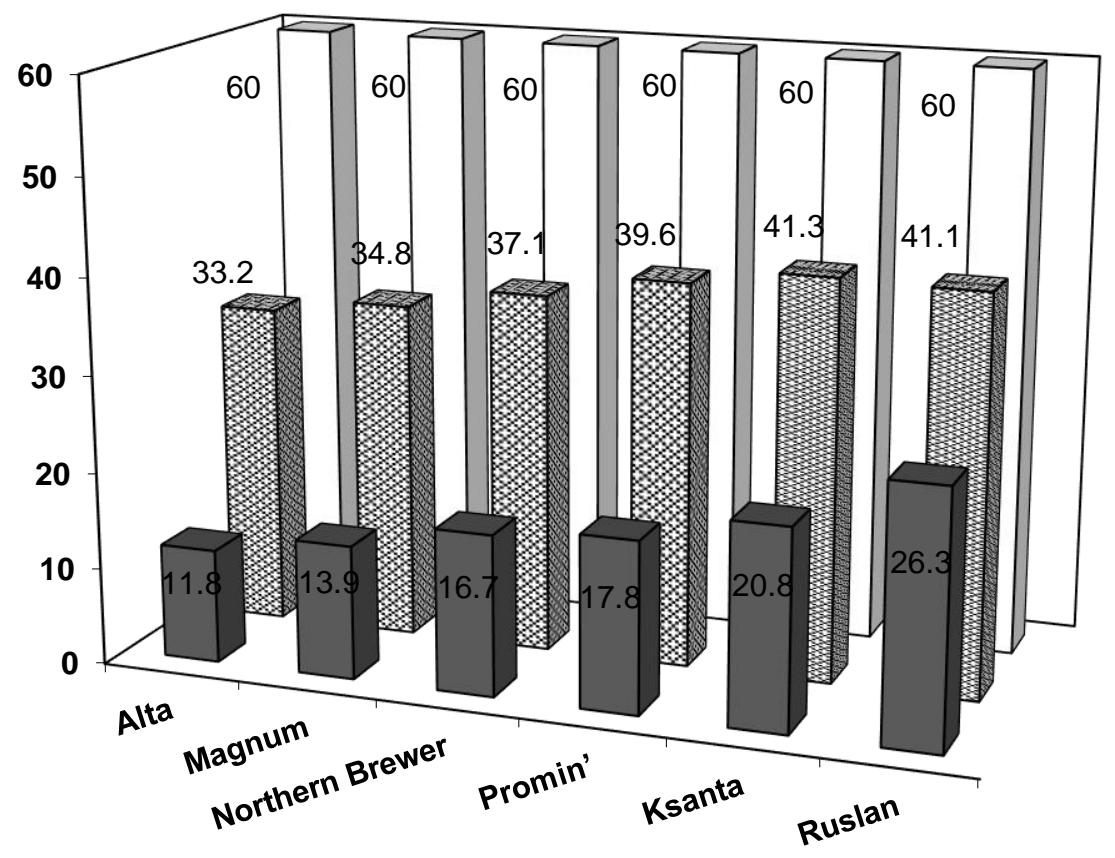

$$
\begin{aligned}
& \square \text { Cohumulone, mg / I } \\
& \text { घBitterness of the wort, un.EBC } \\
& \text { 口Introduced alpha-acids, mg / I }
\end{aligned}
$$

Figure 1. The amount of bitter substances introduced into the wort and identified in it when using bitter hops

From the analysis (Figure 1) we see that with hops of the Ksanta variety in the wort is introduced $76.3 \%$ more cohumulone with alpha-acids compared to hops of the Alta variety which has the lowest content of cohumulone in the composition of alpha acids. At the same time the value of the bitterness of the hopped wort increased by $24.3 \%$ compared to the use of the Alta variety. That is with an increase in the mass fraction of cohumulone in the alpha- 
acids of Ksanta hops by $1 \%$ the value of the bitterness of the hopped wort increases by $0.32 \%$. When the wort is hopped with Ruslan hops with a much higher content of cohumulone in the composition of alpha-acids, the value of the bitterness of the wort practically does not change. But if in Ruslan hops the amount of cohumulone in the composition of alpha-acids was $123.4 \%$ more compared to Alta hops, the value of the bitterness of the wort hopped by this hop increased only by $23.7 \%$ compared to Alta. With an increase in the mass fraction of cohumulone in the composition of alpha-acids of the Ruslan variety by $1 \%$ the value of the bitterness of the hopped wort increases by only $0.19 \%$. After analyzing the relationship between the growth of cohumulone in the composition of alpha-acids and the change in the value of the bitterness of the hops watered by these varieties, it follows that with increasing the share of cohumulone in the composition of alpha-acids of bitter hops by $1 \%$ the bitterness of hop wort increases from 0.19 for the Ruslan variety up to $0.38 \%$ for the Promin' variety. For other studied varieties of bitter type this figure is in the range of $0.27-0.32$. The obtained research data explain why when normalizing hops according to the content of alpha-acids with different content of cohumulone they do not always get stably normalized bitterness of beer because with increasing the share of cohumulone in alpha-acids increases the bitterness of the wort which is consistent with other scientists [16, 19-20].

In Figure 2 shows the correlation field between the bitterness of the wort (axis y) and the amount of cohumulone (axis $\mathrm{x}$ ) introduced when using bitter hops, the regression equation and the coefficient of determination $\mathrm{R}^{2}$ constructed a trend line which is also shown in this figure.

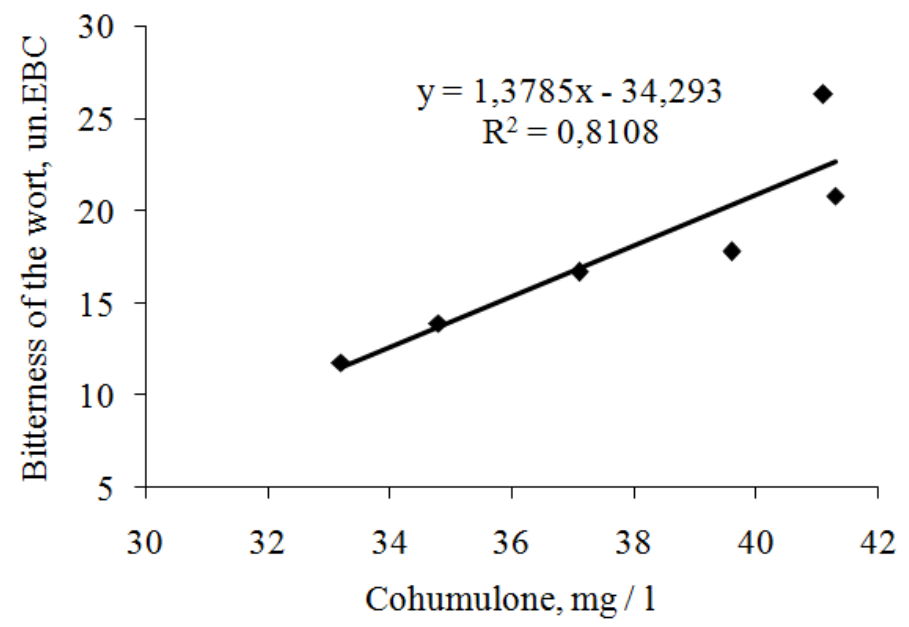

Figure 2. Coreliness of deposits between the must of wort and the amount of wort introduced by cohumulon with hops of rich varieties

The occurrence of the wort and the wort must have been added to the cohumulone with the hops in the case of vicarious vigorous varieties of currencies that are correlated: $y=1.3785 x-34.293$. Among the signs of speeding straight ahead. The coefficient of correlation ( $r=0.90 \pm 0.10)$ shows that there is less wort and more wort introduced to the cohumulone with hops in case of strong vigorous varieties. Some determinants $\mathrm{R}^{2}=0.8108$ per case, $81.08 \%$ of the amount of wort added is due to the amount of wort added to the hop and the $18.82 \%$ was found to be unavailable. 
Studies have shown that when used for hop wort bitter type hops with different alphaacid composition more effective use in varieties with high content of cohumulone which is consistent with the results of studies by other scientists [16, 19-20].

\section{Influence of cohumulone of aromatic varieties of hops on wort quality}

The correlation between the content of cohumulone in the composition of alpha-acids of aromatic varieties and the bitterness of hop wort was investigated in the manufacture of beer samples with aromatic samples of hops.

In the obtained samples of wort, the amount of beta-acids and cohumulone up to 1 liter of wort and the value of the bitterness of the wort were determined which is shown in Figure 3.

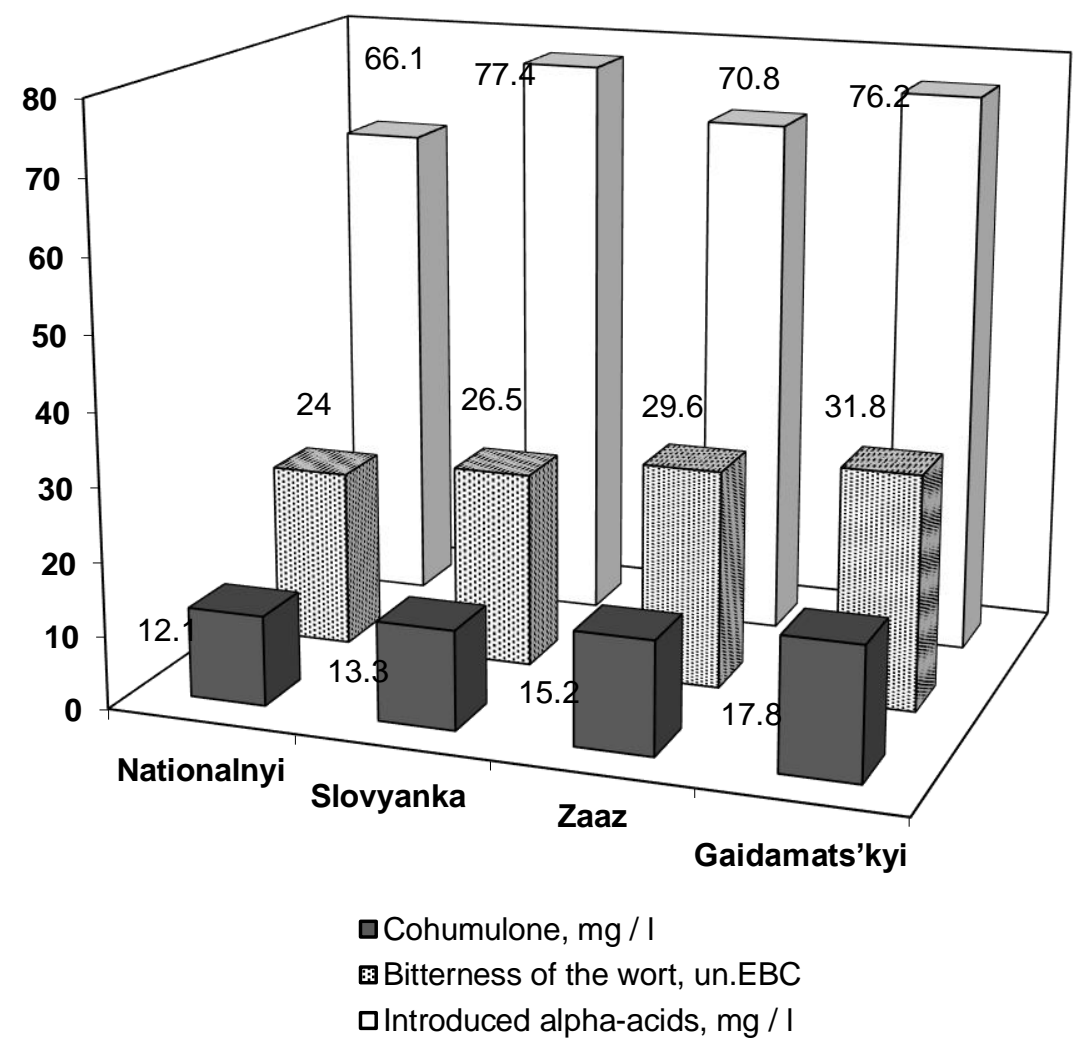

Figure 3. The amount of bitter substances introduced into the wort and determined in it when using aromatic varieties of hops

When the same amount of alpha-acids (about $60 \mathrm{mg} / \mathrm{l}$ ) is added to the wort different amounts of cohumulone are added to the wort: from $12.1 \mathrm{mg} / \mathrm{l}$ with hops of the Nationalnyi variety to $17.8 \mathrm{mg} / \mathrm{l}$ with the Gaidamats'kyi variety. The magnitude of the bitterness of the hopped wort also varies from 24.0 units EBC up to 31.8 units EBC. But if in the hops of the 
Gaidamats'kyi variety the amount of cohumulone in the composition of alpha-acids was $47.2 \%$ more compared to the hops of the Nationalnyi variety which has the lowest content of cohumulone, the value of bitterness of the hop wort hop increased by $32.5 \%$ compared to the Nationalnyi, i.e. with an increase in the mass fraction of cohumulone in the alpha-acids of hops of the Gaidamats'kyi variety by $1 \%$, the value of the bitterness of the hopped wort increases by $0.69 \%$. When using hops of the Slavyanka variety $13.3 \mathrm{mg} / \mathrm{l}$ of cohumulone is added to the wort with alpha-acids which is $9.9 \%$ more than the hops of the Nationalnyi variety and the value of the bitterness of the hop wort increased by $10.4 \%$ compared to Nationalnyi. For hops of this variety with an increase in the mass fraction of cohumulone in the composition of alpha-acids by $1 \%$ the value of the bitterness of the wort hopped by it increases by $1.05 \%$.

In Figure 4 shows the correlation field between the bitterness of the wort and the amount of cohumulone introduced using hops of aromatic varieties.

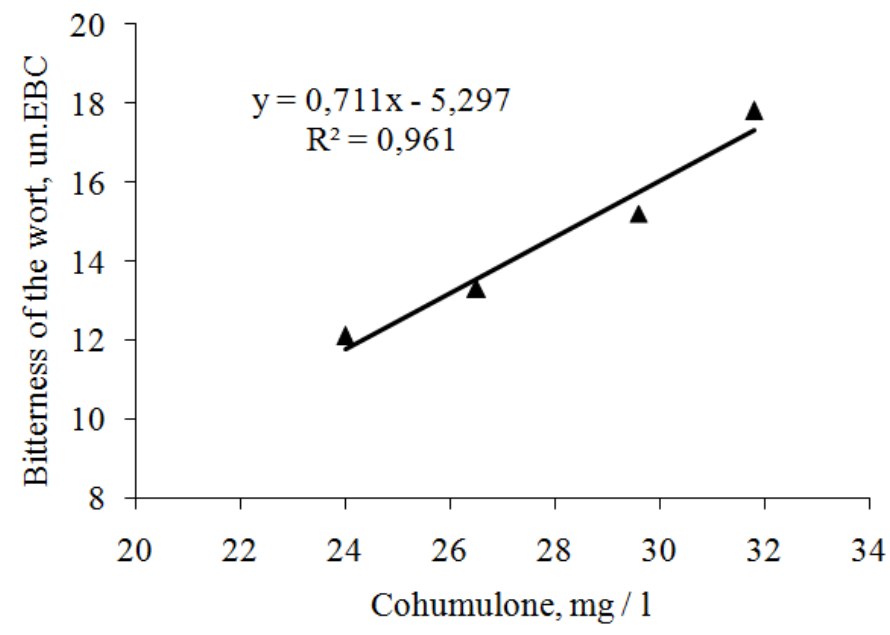

Figure 4. Correlation between the bitterness of the wort and the amount of cohumulone with hops of aromatic varieties

Given the use of aromatic hops, this dependence is expressed by the correlation equation: $y=0,711 x-5,297$. There is a direct connection between the signs. There is a strong correlation between two factors: the bitterness of the wort (axis y) and the amount of cohumulone (axis $\mathrm{x}$ ) added to hops of aromatic varieties, as evidenced by the correlation coefficient $(r=0.98 \pm 0.20)$. The total variation in the bitterness of the wort $(96.10 \%)$ is due to changes in the amount of cohumulone and the remaining $3.90 \%$ is other factors that were not taken into account in this case.

We found that with an increase in the mass fraction of cohumulone in the composition of alpha-acids of aromatic hops by $1 \%$ at a ratio of beta-acids to alpha-acids of 1.11-1.34, the value of the bitterness of the wort hopped by them increases from $0.69 \%$ for hops Gaidamats'kyi variety up to $1.05 \%$ for hops of the Slovyanka variety while for bitter hops in which the ratio of beta-acids to alpha-acids is $0.51-0.74$, this figure was much lower and amounted to only $0.19-0.38 \%$. Thus it was found that in the formation of the bitterness of the wort hopped with aromatic varieties of hops from the ratio of beta-acids to alpha-acids is more than one, the role of beta-acid compounds is much higher compared to bitter varieties. 


\section{Influence of cohumulone of aromatic hops on beer quality}

The established dependences remain and at research of ready beer which characteristic is resulted in Table 3 .

Content of bitter substances and polyphenolic compounds in beer samples

Table 3

\begin{tabular}{|c|l|c|c|}
\hline № & $\begin{array}{l}\text { Variety of hops from which } \\
\text { beer is made }\end{array}$ & $\begin{array}{c}\text { Magnitude of the } \\
\text { bitterness of beer, } \\
\text { units EBC }\end{array}$ & $\begin{array}{c}\text { Total polyphenols, } \\
\text { mg/dm }\end{array}$ \\
\hline 1 & Nationalnyi & 19.3 & 172.0 \\
\hline 2 & Slovyanka & 22.6 & 183.4 \\
\hline 3 & Zaaz & 24.8 & 180.0 \\
\hline 4 & Gaidamats'kyi & 26.1 & 218.0 \\
\hline
\end{tabular}

Sensory evaluation of experimental samples of beer and its biochemical characteristics showed that all samples differed significantly in taste, bitterness and aroma (Table 4).

Technological evaluation of the studied varieties of hops

Table 4

\begin{tabular}{|c|c|c|c|c|c|c|c|c|}
\hline \multirow[b]{3}{*}{ Options } & \multicolumn{8}{|c|}{ Name of quality indicators } \\
\hline & \multirow[b]{2}{*}{ 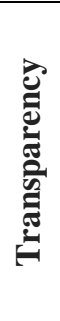 } & \multirow[b]{2}{*}{$\frac{\dot{\theta}}{\dot{\theta}}$} & \multirow[b]{2}{*}{ 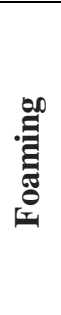 } & \multirow[b]{2}{*}{ 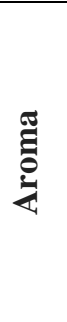 } & \multicolumn{2}{|c|}{ Taste } & \multirow[b]{2}{*}{ 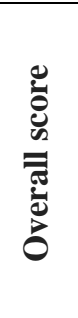 } & \multirow[b]{2}{*}{ 占 } \\
\hline & & & & & 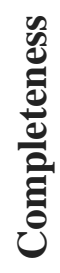 & 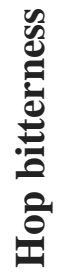 & & \\
\hline Nationalnyi & 3 & 3 & 5 & 3.6 & 4.1 & 4.3 & 23.0 & perfectly \\
\hline Slovyanka & 3 & 3 & 5 & 3.9 & 4.3 & 4.6 & 23.8 & perfectly \\
\hline Zaaz & 3 & 3 & 5 & 3.9 & 4.2 & 4.6 & 23.7 & perfectly \\
\hline Gaidamats'kyi & 3 & 3 & 5 & 3.5 & 3.9 & 3.9 & 22.3 & perfectly \\
\hline
\end{tabular}

Slovyanka and Zaaz obtained the best beer in the case of hop worting with finely aromatic hop varieties. The beer had a pleasant taste, fresh hop of polyphenolic compounds, which are rich in hop of this aroma and a gentle, residual bitterness. Excellent quality was also beer using the aromatic variety of hops Nationalnyi. The fourth sample of beer had good taste, but was inferior in aroma and hop bitterness to other samples. The members of the commission noted a slightly rough astringent bitterness, characteristic of the excessive amount variety.

The members of the tasting commission also noted that in the first sample of beer, in which the lowest amount of cohumulone and beta-acids was added with Nationalnyi hops, the value of beer bitterness was the lowest. With an increase in the content of cohumulone in the composition of alpha-acids from $20.1 \%$ in hops of the Nationalnyi variety to $29.6 \%$ in 
the variety Gaidamats'kyi and with an increase in the amount of cohumulone with these varieties of hops from 12.1 to $17.8 \mathrm{mg}$ to 1 liter of wort, increases the amount of bitterness of beer both spectrophotometric and sensory which is consistent with the data of other scientists $[3,8]$ who also note that ways to create new varieties of hops are intended to maintain the level of cohumulone formation not more than $25 \%$ of total alpha-acids in aromatic hops and 35\% in bitter hops [3, 8]. Thus different representatives of the bitter substances of hops have different bitterness both in total intensity and in individual flavors. Taking into account the maximum qualities of all components of the group of bitter substances allows you to rationally use the most expensive raw materials, creating new beers.

\section{Conclusions}

1. The quality and magnitude of the bitterness of beer depends on the varietal characteristics of hops, i.e., the quantity and quality of homologues of alpha-acids and beta fractions.

2. When used for hop wort hop with a slight deviation of the ratio of beta-acids to alphaacids and different composition of alpha-acids, their use is more effective in varieties with a high content of cohumulone.

3. More intense coarse bitterness in beer is created by cohumulone, so the methods of creating new varieties of hops are intended to maintain the level of cohumulone formation of not more than $25 \%$ of the total alpha-acids content in aromatic hops and $35 \%$ in bitter hops.

4. Establishing the relationship between the quantity and quality of bitter substances of hops and the bitterness and quality of hopped wort and beer which show that with increasing mass fraction of cohumulone in the composition of alpha-acids of aromatic hops by $1 \%$ at a ratio of beta-acids to alpha-acids $1.11-1.34$, the value of the bitterness of the wort hopped by them increases from $0.69 \%$ for hops of the Gaidamats'kyi variety to $1.05 \%$ for hops of the Slavyanka variety, while for bitter hops in which the ratio of beta-acids to alpha-acids $0.51-0.74$, this figure was much lower and was only 0.19 $0.38 \%$.

5. The role of beta-acid compounds in the formation of the bitterness of the wort, hopped with aromatic varieties of hops with a ratio of beta-acids to alpha-acids greater than one is much higher compared to bitter varieties.

\section{References}

1. Lyashenko N.I. (2002), Hops and hop products biochemistry, Polissja, Zhitomir.

2. Protsenko Lidiya, Litvynchuk Svitlana (2015), Competitiveness of Ukrainian pellet hops production, Ukrainian Journal of Food Science, 3(1), pp. 51-59.

3. Podeszwa Tomasz, Harasym Joanna (2016), New methods of hopping (dryhopping) and their impact on sensory properties of beer, Acta Innovations, 21, pp. 79-86.

4. Lyashenko N.I., Mykhajlov M.G. (2010), Curative potential of hop and beer, Agropromyslove vyrobnytstvo Polissja: Zbirnyk naukovykh prats', 3, pp. 50-54.

5. Narziß L. (2005), Abriß der Bierbrauerei. 7th ed., Wiley-VCH: Weinheim, pp. $163-$ 170.

6. Biendl M., Pinzl C. (2007), Arzneipflanze Hopfen. Deutsches Hopfenmuseum Wolnzach, Wolnzach. 


\section{— Food Technology —}

7. Ting Patrick, Ryder David (2017), The Bitter, Twisted Truth of the Hop: 50 Years of Hop Chemistry, Journal of the American Society of Brewing Chemists, 75(3), pp. 161180. DOI: 10.1094/ASBCJ-2017-3638-01.

8. Baranowski K. (2016), Chmielowe akcenty smakowo-zapachowe w piwie? No problem, ale ..., Przemyst Fermentacyjny i Owocowo - Warzywny, 11 pp. 10.

9. Skomra U. (2016), Chmiel zwyczajny (Humulus lupulus L.) Gatunek o szerokim spektrum aktywności biologicznej, Instytut Uprawy Nawożenia i Gleboznawstwa (IUNG), Available at: http://pw.ihar.edu.pl/assets/Uploads/1.2-Koryciny-Skomrakolekcja-chmielu-referat.pdf (dostęp 18.12.2016).

10. Oberholster A., Titus B, (2016), Review: Impact of Dry Hopping on Beer Flavor Stability, Ann Food Process Preserv, 1(1), pp. 1004.

11. Hieronymus S. (2012), For the Love of Hops: The Practical Guide to Aroma, Bitterness and the Culture of Hops, Boulder, Brewers Publications, a division of the Brewers Association, Colorado.

12. Drexler G. (2016), Dry Hopping, Barth-Haas Hops Academy, Blumenau Available at: http://www.cervecon.com.br/Palestras/Georg_Drexler.PDF (access 18.12.2016).

13. Forster A., Gahr A., (2013), On the fate of certain hop substances during dry hopping, BrewingScience, 66(7-8), pp. 93-103.

14. Schnaitter M., Kell A., Kollmannsberger H., Schüll F., Gastl M., Becker T. (2016), Scale-up of Dry Hopping Trials: Importance of Scale for Aroma and Taste Perceptions, Chem Ing Tech, 88(12) pp. 1955-1965.

15. Forster A., Gahr A., Van Opstaele F. (2014), On the transfer rate of geraniol with dry hopping, BrewingScience, 67(3-4), pp. 60-62.

16. Jessika De Clippeleer, Guido Aerts (2014), Beer's bitter compounds - A detailed review on iso-a-acids: Current knowledge of the mechanisms for their formation and degradation, Brewing Science, 67(11), pp.167-182.

17. Paulo Alves da Silva, Fernanda Carolina de Faria (2008), Bitterness Unit and iso-alfaacids contents of some brands of Brazilian and North American beers, Ciência $e$ Tecnologia de Alimentos, 28(4), pp. 902-906.

18. Shellhammer T. (2004), Bitter quality of beer as affected by isocohumulone levels, Proceedings of the World Brewing Congress, San Diego.

19. Kusche M., Stettner G., Stephan A., Mitter W., Kaltner D. (2007), Influence of the new high alpha hop variety Herkules on beer quality, Proceedings of the European Brewery Convention Congress, Venice.

20. Malowicki M. G., Shellhammer T. H. (2006), Factors affecting hop bitter acid isomerization kinetics in a model wort boiling system, J. Am. Soc. Brew. Chem., 64, pp. 29-32.

21. Protsenko Lidia, Rudyk Ruslan, Hryniuk Tetiana, Vlasenko Aliona, Protsenko Alona, Litvynchuk Svitlana, Ovadenko Olena (2018) Beer enrichment with biologically active hop compounds, Ukrainian food journal, 7(1), pp. 65-78, DOI: 10.24263/2304-974X2018-7-1-7.

22. Biendl M., Virant M., Varjú P. (2004), Determination of iso-alpha-acids, alpha- and beta-acids in isomerised hop pellets by HPLC, J. Inst. Brew., 110, pp. 242-243.

23. Ahalitika - EBC (1987), European Brebery Convention, Fourth edition.

24. Jaskula B., Goiris K., De Rouck G., Aerts G., De Cooman L. (2007), Enhanced quantitative extraction and HPLC determination of hop and beer bitter acids, J. Inst. Brew., 113, pp. 381-390. 